\title{
A condição internacional de Taiwan e a abertura de canais diplomáticos submersos como janela de oportunidade: o caso do CSCAP*
}

Jorge Tavares da Silva'

\section{Resumo}

O presente ensaio centra-se no caso singular da ilha de Taiwan, um Estado de facto no contexto asiático sem o ser de jure, por falta de reconhecimento da comunidade internacional, que deixa o território num estado de isolamento excepcional na arquitectura institucional global. Incapaz de participar em muitos organismos regionais, em especial aqueles que incidem em questões de segurança, a Formosa não consegue levar às plataformas de discussão multilateral o conflito que a opõe à República Popular da China (RPC). Os insulares têm aproveitado um conjunto de processos e redes de natureza submersa, realizados entre actores não oficiais, de que o The Council for Security Cooperation in the Asia Pacific (CSCAP) se tem revelado um bom exemplo.

Palavras-Chave: China. Taiwan. Conflito. Diplomacia submersa. Transformação. CSCAP.

* Recebido em 26.09.10.

Aprovado em 25.11.10.

1 Licenciado em Comércio Internacional pelo ISCIA (Instituto Superior de Ciências de Informação e Administração), Aveiro (Portugal), foi docente desta instituição nos anos de 2006 e 2007. É autor de diversos artigos sobre a realidade política e económica chinesa, e tem participado em conferências nacionais e internacionais sobre a mesma matéria. Actualmente é doutorando em politica internacional e resolução de conflitos na Faculdade de Economia da Universidade de Coimbra, em associação com o Centro de Estudos Sociais (CES) e financiada pela Fundação para a Ciência e Tecnologia (FCT). É membro fundador do Observatório da China, membro da Associação Cultural PortugalChina, do Instituto Português de Sinologia, da European Association for Chinese Studies, e da Association of Chinese Political Studies E-mail: jts.ave@gmail.com 


\section{Introdução}

Desde a década de 1970 que a ilha de Taiwan tem sentido dificuldades em resistir ao isolamento internacional que foi votada, tendo actualmente apenas relações diplomáticas com vinte e três pequenos países e a participação condicionada num número reduzido de organismos internacionais ${ }^{2}$. $\mathrm{O}$ conflito que a opõe à China Popular deixa poucas oportunidades às instituições e aos actores habilitados na transformação ou resolução de conflitos. A Questão de Taiwan permanece para Pequim como um assunto interno e, portanto indisponível para ser abordada em instituições de natureza multilateral e oficial. Ainda assim, fruto de uma nova arquitectura regional e do florescimento de um conjunto de novos organismos vocacionados para o desenvolvimento e segurança, Taipé tem conseguido participar em algumas plataformas informais sob determinadas condições. O presente ensaio vai ao encontro das interacções deste tipo, as quais designamos de forma geral por $d i$ plomacia submersa, entre as quais daremos uma atenção particular àquelas desenvolvidas pelo CSCAP. Pretendemos apurar quão relevantes têm sido as dinâmicas deste tipo no âmbito deste organismo e como se processa o seu funcionamento. Em termos estruturais, começaremos por uma breve abordagem aos contornos principais do conflito, em especial os factores que conduziram ao estado de impasse e ao isolamento internacional de Taiwan. Partindo deste cenário, focalizar-nos-emos na diplomacia submersa, nas suas principais particularidades de forma a perceber quão proveitosa tem sido a abertura daquele tipo de dinâmicas para a transformação do conflito entre a China e Taiwan.

\section{Da génese do conflito ao estado de impasse}

O conflito de Taiwan, grosso modo, representa uma reminiscência da guerra civil chinesa, que assolou o Império do Meio na primeira metade do século XX, e a

\footnotetext{
2 A República da China (ROC), mantém relações diplomáticas com os seguintes países: Em África, com o Burquina Faso, a Gâmbia, São Tomé e Príncipe e a Suazilândia; na América Central e do Sul, com o Belize, a Republica Dominicana, El Salvador, a Guatemala, o Haiti, as Honduras, a Nicarágua, o Panamá, o Paraguai, São Cristóvão e Nevis, Santa luzia, São Vicente e Granadinas; na Europa com o Vaticano e na Oceânia, com o Kiribati, as Ilhas Marshall, Nauru, Palau, as Ilhas Salomão e Tuvalu.
} 
consequência da disputa ideológica e territorial protagonizadas pelas duas grandes potencias mundiais no período da Guerra-Fria (SILVA, 2008, p. 321). A génese do conflito remonta ao inicio do século XX, quando a China vivia o fim da era imperial, marcada com a abdicação do último imperador manchu (1912). Este episódio foi coincidente com um estado de insegurança generalizado, sob a ameaça de invasão das potências estrangeiras, caos, risco de movimentos separatistas e delapidação do tesouro nacional (SPENCE, 1996, p. 275). A influência estrangeira em algumas elites chinesas, estimulou o aparecimento de vários grupos revolucionários, um dos quais liderado por Sun Yat-sen, que seria o primeiro presidente provisório, em Fevereiro de 1912. A posterior morte deste líder, em 1925, depois de uma alternância de poder com o comandante do exército do Norte, Yuan Shikai, deixaria aberta uma luta pelo poder entre o Partido Nacionalista do Povo, também conhecido por Guomindang (GMD), comandado por Chiang Kai-Shek, os comunistas, liderados por Mao Zedong, e ainda alguns grupos de senhores da guerra. Os nacionalistas estabeleceram a capital do país em Nanjing, e em 1923 fazem uma espantosa aproximação aos comunistas para pouco depois os perseguirem, dando início a uma guerra civil fratricida. Com a invasão japonesa os comunistas e nacionalistas voltariam a unir-se, mas com a derrota do Japão na II Guerra Mundial voltam a digladiar-se. Em 1949, as forças comunistas triunfam em todo o território chinês e, finalmente, é proclamada a RPC e o seu líder máximo Mao Zedong. Enquanto a china surge novamente reunificada pelos comunistas, o general Chiang Kai-Shek refugia-se na ilha de Taiwan, onde instala a República da China (ROC) e deixa em aberto o processo de reunificação total. O GMD tinha perdido o controlo sob a maior parte do território, mantendo-se as suas forças apenas em Taiwan, Pescadores e algumas ilhas pequenas como Jinmen e Matsu (LIN; KEATING, 2008, p. 61).

O auxílio económico e militar de Washington, que inclui o envio da $7^{\mathrm{a}}$ esquadra para o Estreito de Taiwan, vai permitir aos nacionalistas resistir ao ímpeto comunista. O envolvimento chinês na guerra da Coreia tinha despertado as sirenes de alarme americanas contra o expansionismo comunista na região da Ásia-Pacífico. Com a ingerência de Washington a guerra civil seria estancada, mas ficaria aberta uma ferida política que perduraria até aos dias de hoje. A Chegada em massa dos nacionalistas à ilha de Taiwan em 1949 coloca as populações locais em mais uma situação de ocupação externa, enquanto a existência de duas repú- 
blicas chinesas deixa a ONU com um problema de reconhecimento diplomático por resolver ${ }^{3}$. A China nacionalista de Chiang Kai-shek, por influência dos EUA, tinha o estatuto de uma das cinco grandes potências, sendo membro permanente do Conselho de Segurança com direito de veto desde 1945. A partir daqui a China Popular vai procurar a representação no seio da $\mathrm{ONU}^{4}$, mas sistematicamente seria boicotada pelos EUA até 1972, o que segundo Ramón Tamames e Begoña G. Huerta (2000, p. 509-510), tratou-se de uma manifestação, segundo eles, provavelmente a mais ostensiva, do imperialismo americano, ao não reconhecer a um país de mais de 800 milhões de habitantes da altura, o protagonismo que lhe correspondia nos destinos do mundo. Em vez disso, a Formosa, com pouco mais de 14 milhões de habitantes ocupava um lugar de destaque que não lhe competia. $\mathrm{O}$ isolamento internacional de Pequim manteve-se até aos anos 70, em que apenas o Reino Unido, a França, alguns países escandinavos e umas dezenas de países do denominado terceiro mundo tinham embaixadas na capital chinesa. Em 1971, a Assembleia-Geral da ONU votou favoravelmente o reconhecimento da RPC como únicos e legítimos representantes da China naquele organismo, ao passo que ficou deliberado expulsar os representantes nacionalistas para grande surpresa americana. A partir de 1972, com o restabelecimento das relações diplomáticas entre os EUA e a China, que incluiu o encontro entre Nixon e Mao, e o posterior reconhecimento mútuo e o estabelecimento formal de relações de 1978 (CUNHA, 2008, p. 37-47), a situação agrava-se e a ROC cai num progressivo isolamento internacional, embora tenha recebido protecção militar através do Taiwan Relations Act (TRA). Fruto da estratégia de ambiguidade de Washington a situação mantém-se inalterada, ora passando por períodos de maior cooperação, com outros de enorme crispação.

\footnotetext{
3 As forças nacionalistas instalaram-se no território desde 1945, logo após a capitulação do Japão, com cerca de 20000 soldados e 200 oficiais mas a desorganização e má conduta das tropas provocou a indignação das populações, pelo que a chegada em massa em 1949, foi sentida e aumentou a população da ilha com mais 2 milhões de pessoas (LIN; KEATING, 2008, p. 57-61).

4 Em Novembro de 1949 o Governo da China Popular, através do Ministro dos Negócios Estrangeiros, Chou En-lai, envia um telegrama ao Secretário-Geral da ONU, Trygve Lie, dando-lhe a conhecer de que os "nacionalistas deixaram de ter capacidade para representar o povo chinês" naquele organismo (CUNHA, 2008, p. 33 apud Noticias de Macau).
} 


\section{As vulnerabilidades de Taiwan no sistema internacional}

Desde a década de 1970, fruto dos acontecimentos apresentados anteriormente, Taiwan passa a viver entre os interesses geopolíticos de Washington, que vai seguindo uma política de ambiguidade estratégica, e a intransigente politica de unidade nacional de Pequim. O governo taiwanês obriga-se a seguir uma soberania funcional, reconhecida internamente pelo poder normativo dos factos, mas sendo internacionalmente desprovida de reconhecimento, aparecendo na catalogação dos denominados povos mudos, assim denominados por Sukarno (MONTEIRO, 2001, p. 24; CUNHA, 2008, p. 97). A situação difícil destes povos levou à criação de uma associação fundada em 1991 em Haia, designada por Organização das Nações e Povos Não Representados (UNPO), que procura a representação de 50 milhões de pessoas em todo o mundo sem voz internacional.

Tendo a RPC o direito de veto no Conselho de Segurança das Nações Unidas, a adesão de Taiwan às organizações internacionais torna-se um processo muito difícil, apesar de ter o estatuto de Estado com governo. Desde 1993 que a ROC tem intensificado a tentativa de representação na ONU, mas apesar de algum apoio internacional, tal como a resolução do Parlamento Europeu de 1997, pedindo mais representação internacional para Taiwan, a ONU tem rejeitado a proposta dos aliados de Taiwan para colocar a questão na agenda. Em alguns casos Pequim vai usando o seu poder de veto para actuar contra o que se poderá designar por estados inimigos, ou seja, aqueles que teimam em apoiar a posição taiwanesa. Em 1997 e em 1999, por exemplo, a China vetou as resoluções para estabelecer uma missão de observação na Guatemala e para renovar outra na macedónia, devido ao facto de que estes países tinham relações diplomáticas com Taiwan (WOUNTERS; RUYS, 2005, p. 11). Em relação a Taipé, poderemos dizer que segue uma politica com dualidade de critérios, por um lado vai tentando seduzir os formosinos, por outro mostrando-lhe a possibilidade de usar a força. Esta postura não retira vontade a Taiwan de tentar participar nos organismos internacionais que mais lhe interessam. Um dos casos mais conhecidos é o esforço para participar na Organização Mundial de Saúde (OMS), com vista a proteger os direitos de saúde dos seus 23 milhões de habitantes. A verdade é que se trata de um país que muito tem contribuído para o desenvolvimento do sector da saúde, em especial no combate a algumas pandemias que ameaçaram a região asiática. Taipé consegue participar 
neste organismo declarando que se as doenças não têm fronteiras, as iniciativas pela saúde devem ser verdadeiramente internacionais. Desde 2008, no entanto, com a administração de Ma Ying-jeou, a ROC tem encontrado um maior espaço de cooperação e a RPC permitiu a participação a assembleia anual da OMS em Maio de 2009 como observador, fazendo uso da designação de Chinese Taipei. Mas se a ilha permanece condicionada nos trabalhos deste organismo, noutros esforços por representação têm dado os seus frutos. Em 2002, Taiwan tornou-se membro de pleno direito na Organização Mundial de Comércio (OMC), embora sobre a designação de Separate Customs Territory of Taiwan, Penghu, Kinmen, and Matsu. Taiwan participa ainda em 27 outras organizações internacionais, incluindo o Banco de Desenvolvimento Asiático (ADB), na figura de observador, mas também como membro associado em 21 outras, muitas vezes aparecendo classificada por Chinese Taipei (figura 1). O Fórum Boao, por exemplo, é uma organização não governamental e sem fins lucrativos que junta lideres de governos, de negócios e académicos da Ásia e de outros continentes para partilhar visões em questões relevantes (BOAO FORUM, 2010). As delegações têm oportunidade de discutir com os quadros oficiais da RPC em matérias de interesse bilateral. Alguns analistas dizem que os encontros no Boao Forum e a Exposição Mundial de Shanghai permitem que pessoas influentes de ambos os lados do Estreito se encontrem, representando uma boa oportunidade para "testar as águas" e verificar que questões adicionais a China pretende negociar (TAIWAN TODAY, 2010). 
Figura 1. Quadro com a participação e estatuto de Taiwan em alguns organismos internacionais.

\begin{tabular}{|c|c|c|c|}
\hline Organismo & Designação & Organismo & Designação \\
\hline $\begin{array}{c}\text { Fundo } \\
\text { Monetário } \\
\text { Internacional } \\
\text { (IMF) }\end{array}$ & Chinese Taipei & $\begin{array}{c}\text { Comité } \\
\text { Internacional da } \\
\text { Cruz Vermelha } \\
\text { (ICRC) }\end{array}$ & $\begin{array}{c}\text { Republic of } \\
\text { China }\end{array}$ \\
\hline $\begin{array}{c}\text { Comité } \\
\text { Olímpico } \\
\text { Internacional } \\
\text { (IOC) } \\
\end{array}$ & Chinese Taipei & $\begin{array}{c}\text { Confederação } \\
\text { Mundial do Trabalho } \\
\text { (WCL) }\end{array}$ & Taiwan \\
\hline $\begin{array}{l}\text { Organização } \\
\text { Mundial de } \\
\text { Saúde (WHO) }\end{array}$ & $\begin{array}{l}\text { Chinese } \\
\text { Taipei } \\
\text { (Observador) }\end{array}$ & $\begin{array}{c}\text { Organização } \\
\text { Mundial de Saúde } \\
\text { Animal (WOAH) }\end{array}$ & Taipei China \\
\hline $\begin{array}{l}\text { Banco Mundial } \\
\text { (WB) }\end{array}$ & Chinese Taipei & $\begin{array}{c}\text { Banco de } \\
\text { Desenvolvimento } \\
\text { Asiático }(\mathrm{ADB})\end{array}$ & Chinese Taipei \\
\hline $\begin{array}{c}\text { Banco Centro- } \\
\text { Americano } \\
\text { de Integração } \\
\text { Económica } \\
\text { (BCIE) }\end{array}$ & $\begin{array}{c}\text { Republicf } \\
\text { China }\end{array}$ & $\begin{array}{c}\text { Sistema de } \\
\text { Integração Centro- } \\
\text { Americana (SICA) }\end{array}$ & $\begin{array}{c}\text { Republic } f \\
\text { China }\end{array}$ \\
\hline $\begin{array}{c}\text { Câmara de } \\
\text { Comércio } \\
\text { Internacional } \\
\text { (ICC) }\end{array}$ & $\begin{array}{c}\text { Republic of } \\
\text { China }\end{array}$ & $\begin{array}{c}\text { Organização das } \\
\text { Nações e Povos } \\
\text { Não Representados } \\
\text { (UNPO) }\end{array}$ & Taiwan \\
\hline $\begin{array}{c}\text { Conselho de } \\
\text { Cooperação } \\
\text { sobre Segurança } \\
\text { na Ásia } \\
\text { (CSCAP) }\end{array}$ & $\begin{array}{c}\text { Participation } \\
\text { with individual } \\
\text { capacity }\end{array}$ & $\begin{array}{c}\text { Organização } \\
\text { Mundial do } \\
\text { Comércio (WTO) }\end{array}$ & $\begin{array}{c}\text { Separate } \\
\text { Customs } \\
\text { Territory } \\
\text { Taiwan, Pengu, } \\
\text { Kinmene } \\
\text { Matsu }\end{array}$ \\
\hline $\begin{array}{c}\text { Forum Boao } \\
\text { para a Ásia } \\
\text { (BFA) }\end{array}$ & Chinese Taipei & $\begin{array}{c}\text { Cooperação } \\
\text { Económica Ásia- } \\
\text { Pacifico (APEC) }\end{array}$ & Chinese Taipei \\
\hline
\end{tabular}


Importa salientar que a maior parte dos organismos em que Taiwan participa são de natureza económica, ou estão vocacionados para as questões do desenvolvimento. No entanto, as questões de segurança, que seriam de extrema importância para o futuro das relações com a China Popular estão alheadas dos fóruns de discussão regional. É bem verdade que muitos fóruns de natureza económica têm servido mais facilmente como plataformas de diálogo para questões de segurança, porque não provocam um efeito de rejeição tão evidente por supostamente tratarem de matérias menos belicosas. Taiwan não participa na ASEAN e nem na ASEAN Regional Forum (ARF), onde poderia de forma multilateral procurar debater e encontrar soluções para o conflito. Limitada nas relações governamentais, é na denominada diplomacia submersa, tanto através de processos comunicacionais como através de dinâmicas espontâneas em rede, que o conflito entre a China e Taiwan tem encontrado muitos elementos positivos para o apaziguamento das tensões.

\section{A singularidade das dinâmicas submersas}

A cena internacional continua a contar com um conjunto considerável de estados irregulares, como são os casos do Sara Ocidental, da Palestina e de Taiwan, onde apesar de poderem ser considerados estados de facto, não o são de jure. Limitadas na sua acção diplomática, ganham força as interacções que denominamos por submersas, enquadradas no campo da nova diplomacia. Trata-se de uma nova forma de abordagem nas relações internacionais que, face ao progressivo enfraquecimento do poder dos Estados, coloca os cidadãos a partilharem muitas das tarefas anteriormente feitas apenas pelos governos (diplomacia oficial). As operações de peacekeeping, por exemplo, passaram a ser desempenhadas por entidades diversas, quer colectivas ou individuais, confirmando a máxima de que "a paz não é estabelecida entre líderes, mas entre povos" (GARRISON; PHIPPS, 1989; MCDONALD, 1993). Esta nova tendência, que não exclui as dinâmicas oficiais (de governo para governo), mas que com elas colaboram, pode incluir diversos níveis de abordagem (figura 2). 
Figura 2. Esquema que procura representar a diplomacia formal e informal e os diversos níveis de envolvimento.

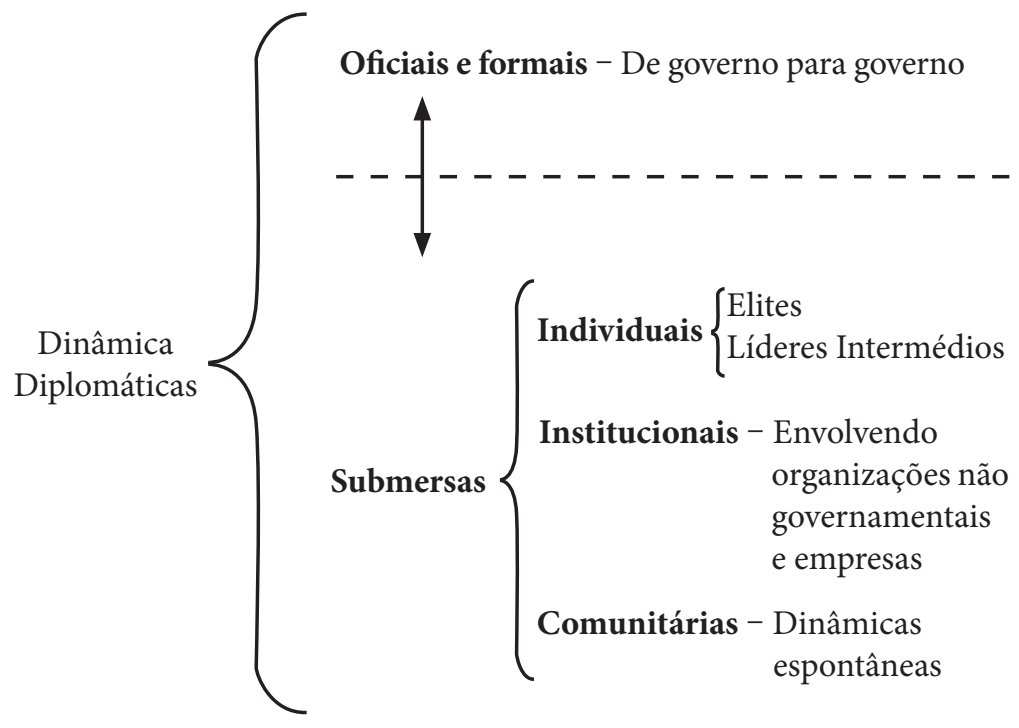

Num primeiro nível, encontramos os líderes religiosos, militares ou empresariais capazes de interceder nos meios políticos devido à enorme capacidade negocial. Num segundo nível, encontramos as ONGs, as empresas e outras associações, não personalizadas, variando a sua capacidade de influência conforme a estrutura e capacidade financeira de cada uma. Muitas são convidadas a participar em conferências e workshops relacionadas com questões de segurança, direitos humanos e paz, entre outros assuntos. Finalmente, num terceiro nível, encontramos as comunidades e as dinâmicas colectivas a ela associadas, de fenómenos como o turismo, a cultura, o desporto ou o comércio. Tratam-se de interacções colectivas, espontâneas motivadas por necessidades do dia-a-dia, as quais não se coadunam com os processos lógicos de problem-solving. As dinâmicas espontâneas criam uma espécie de local knowledge, em que as situações correntes colocam o pensamento está ao serviço da acção. Em vez de se aplicarem técnicas formais de aproximação, as pessoas desenvolvem soluções de oportunidade (ROGOFF, 1999, p. 7). Este fenómeno conduz à participação das pessoas nos processos de paz, ainda que por vezes não de forma consciente, ao seu empowerment e à criação sustentada de capacity-building. 
As dinâmicas submersas actuam como transformadores de conflitos de sociedades divididas, melhorando a comunicação, a compreensão e as relações pessoais. Há um pressuposto que a familiaridade promove o decréscimo dos efeitos negativos das tensões, medo, ou incompreensão, através da humanização da face do inimigo e dando às pessoas a experiência directa no contacto com o outro. Esta é uma estratégia de bottom-up, que ajuda a construir pontes de compreensão, aumenta a confiança, corrige incompreensões, ajuda a mudar a atitude do outro, uma forma de abrir canais de comunicação, e alterar as percepções do conflito. É igualmente uma boa forma para desenvolver redes sociais entre actores de diferentes lados (WEISSEMAN, 2008, p. 70-71), e um meio de transmissão importante para a diplomacia oficial, afectando o pensamento e a acção desta. A diplomacia submersa focaliza-se nas causas profundas, crenças e necessidades humanas, muitas vezes imperceptíveis nas plataformas de diálogo governamentais (DIAMOND; MCDONALD, 1996, p. 2). No início, este tipo de interacção estava limitada aqueles que eram profissionais na resolução de conflitos, mas aos poucos começaram a envolver outras pessoas, entidades e iniciativas, incluindo problem solving workshops, diálogos, trocas culturais e científicas, trocas de artistas, delegações comerciais e equipas desportivas (NOTTER; MCDONALD, 1996).

\subsubsection{Taiwan na esfera da informalidade}

No caso concreto de Taiwan, sabemos que as limitações diplomáticas e políticas conduzem a ilha para as dinâmicas submersas, só comparável às dinâmicas desenvolvidas pelo povo palestiniano. A experiência daquele território tem ganho com aquele tipo de interacções uma ajuda considerável no relacionamento com Pequim, a que se junta o desenvolvimento de uma rede de relações informais (WU, 2009 , p. 8). Trata-se de um fenómeno que não é estranho à matriz cultural local, pois a Ásia tem uma tendência natural para a informalidade, visível no código de conduta estabelecido entre os membros da ASEAN, cujo modelo é caracterizado por ASEAN Way. Também as redes pessoais, conhecidas por guanxi, e que representam um elemento essencial da cultura chinesa, são um fenómeno indissociável àquela região. 
O quadro geral das relações submersas entre a China e Taiwan é diversificado e complexo, envolvendo actores de várias proveniências, por vezes actuando em dinâmicas espontâneas, sem regras ou estrutura, motivados pelas práticas sociais. Noutras, poderão envolver acções estruturadas e processos deliberados como problem solving workshops ou outras iniciativas do mesmo género. Destacamos, nas relações sino-formosinas o papel desempenhado por duas associações semi-oficiais criadas por cada uma das partes com vista ao estabelecimento das relações bilaterais: A Straits Exchange Foundation (SEF), com sede em Taipé, e a Association for Relations Across the Taiwan Straits (ARATS), com sede em Pequim. A iniciativa nasceu em Hong Kong no início da década de 1990, através de vários homens de negócio, tendo conduzido a vários encontros informais e secretos. Após um período de algum esfriamento, a chegada de Ma Ying-jeou (2008) trouxe a reabilitação daqueles organismos. Em termos de redes directas entre os dois lados do Estreito, são importantes as dinâmicas de sectores como o turismo, mas também os os fluxos culturais e desportivos, os negócios e a religião, entre outros possíveis de verificar. Todos eles contribuem para a intensificação das relações sociais e da interdependência, que de uma forma espontânea e gradual contribuem para uma maior harmonia na região. Destacamos o papel da Tzu Chi Association (Ciji), e do seu líder Zhengyan, cujas actividades humanitárias na China Popular tem sido um factor de integração na região (LIBERTÉ, 2004, p. 86). Também a comunidade empresarial taiwanesa a operar na China Popular, também conhecidos por Taishang, têm desempenhado um papel importante não só nos contactos desenvolvidos através da esfera politica, como através das dinâmicas económicas ou até nas acções de responsabilidade social. Em termos indirectos, ou seja através de plataformas de diálogo de natureza multilateral, ainda que de forma condicionada, destacamos além da participação de Taiwan na APEC e no Fórum Boao, bem como na OMC. Apesar de versarem o desenvolvimento económico não deixam de, por um lado, construir laços de cooperação com Pequim e, por outro, abordar temas fora da agenda. Mais importante, por ter uma natureza eminentemente informal, é a participação condicionada de individualidades de Taiwan no fórum do CSCAP, de que falaremos com maior detalhe a seguir. 


\section{0 caso do CSCAP}

A criação do CSCAP em 1993, enquadrado no guarda-chuva institucional da ASEAN e ancorado ao ARF, veio ao encontro do preenchimento das lacunas deste último organismo, ao procurar acolher e promover de forma consistente as iniciativas de natureza submersa. Em boa verdade, o ARF, sobretudo nos seus Annual Ministerial Meetings, já desenvolvia dinâmicas daquele género, mas estas careciam de uma maior universalidade (EVANS, 2000, p. 163). Aquele organismo visa aproveitar os esforços das Organizações Não Governamentais (ONGs) na procura de ideias para as questões de segurança, mas não deixa de envolver também quadros oficiais nas suas qualidades privadas. Ainda que se procure a independência quanto a um possível controlo governamental, reconhece-se que o envolvimento oficial é necessário para a disponibilidade de recursos e assegurar que os trabalhos sejam apreciados pelos órgãos oficiais. Por outro lado, sabe-se que as ONGs promovem o regionalismo através da cooperação económica, o que significa o alcance de estádios de confiança mútua. $\mathrm{O}$ aparecimento deste organismo não visava a criação de uma nova estrutura, mas o aproveitamento de esforços já construídos na região, nomeadamente a ASEAN Institutes for Strategic and International Studies (ASEAN-ISIS), os mais avançados na região em termos de infra-estruturas, práticas e capacidade de cooperação (BALL et al, 2006, p. 175-176). O CSCAP é uma instituição composta por 21 membros nacionais e um observador, vocacionada para a promoção da cooperação e do diálogo nas questões de segurança regional, sendo dotado de uma substancial dose de autonomia capazes de explorar e reinventar as oportunidades criadas. É uma instituição intermediária entre grupos importantes da sociedade civil, como institutos, universidades, NGOs e até empresas, e a esfera governamental (EVANS, 2000, p. 163). O CSCAP tende a provocar um efeito de peneira sobre os contactos diplomáticos da região, crivando as dinâmicas não abrangidas pela diplomacia oficial devido à rigidez dos organismos, em que se inclui o intocável principio de não ingerência, assim como as limitações e vulnerabilidades de algumas lideranças politicas. A função mais importante deste organismo é filtrar os contributos da investigação académica e outras discussões submersas, através dos seus grupos de trabalho, e leva-las a diplomatas e quadros de segurança dos países membros. Não deixando de cooperar com os mecanismos oficiais e formais, até porque os seus actores vitais são antigos membros de governos, aquele organismo através da reorientação de grupos de trabalho, o primeiro 
dos métodos usados, permite-lhe centrar-se nos tópicos pretendidos e de maior interesse político. Encontramos vários exemplos de sucesso alcançados com os workshops, cujos especialistas envolvidos levaram, por exemplo, à harmonização do uso de tecnologias nas exportações, emissão de um memorando sobre protocolos de cooperação marítima, estudos sobre desenvolvimento da capacidade regional em acções de peacekeeping e consultas com o ARF sobre conceitos e princípios de diplomacia preventiva (WILLIAMS; JOB, 2007, p. 7-10). A grande vantagem do CSCAP em relação ao ARF é a sua maior flexibilidade, independência, informalidade e, sobretudo, o seu carácter inclusivo, ao procurar acolher membros ou participantes para lá da esfera estatocêntrica.

Taiwan, por intransigência de Pequim, não consegue participar naquele organismo de importância vital para as questões de segurança regional, sendo a questão de Taiwan um dos conflitos que mais ameaça a estabilidade local e até mundial. $\mathrm{O}$ não tratamento desta questão no âmbito do ARF é contrario ao espírito das relações internacionais contemporâneas, pois as questões de segurança encontram normalmente espaço no sistema multilateral. A criação do CSCAP, através das suas dinâmicas de natureza submersa, ainda que não como membro ordinário e limitada na agenda, trouxe uma nova oportunidade para a ilha participar neste tipo de diálogos. Pequim começou por colocar em causa a natureza não oficial deste organismo, pelo facto de muitos membros governamentais regionais participarem no processo, temendo que Taipé usasse a diplomacia submersa para tentar desbloquear o isolamento diplomático. Não é de estranhar que nos primeiros anos de funcionamento daquele organismo a adesão da Formosa e da China Popular dominasse as discussões do comité permanente. A China opta por ver o CSCAP como sendo essencialmente semi-governamental em vez de não-governamental, pelo que só em 1995 é se junta a este organismo, mas apenas depois de esclarecer que a participação de Taiwan será, como noutros organismos, sobre "very controlled conditions" (LANTEIGNE, 2005, p. 95).

Taiwan, por ter pouca capacidade negocial, ficou sujeito a um conjunto de concessões que favorecem enormemente a posição chinesa. Assim, os representantes formosinos passaram a ter permissão para participar em grupos de trabalho apenas no papel de independentes, pelo que qualquer tipo de representação oficial 
não seria permitida, inclusive o caso de think thanks. Por outro lado, os diálogos directamente relacionados com a questão de Taiwan não poderão entrar na agenda, o que acontece também com outras temáticas, como por exemplo a questão dos refugiados da Coreia do Norte. Desde então, Taipé tem participado nestes diálogos, ainda que de forma condicionada, representando uma janela de oportunidade extraordinária para debater questões importantes do foro da segurança regional e interagir com quadros da China continental. Estas dinâmicas permitem entender com maior clareza as percepções mútuas sobre o conflito, por vezes distorcidas pela formação de barreiras, e recuperar ideias capazes de ser transportadas para a esfera oficial e melhorarem a relação bilateral. Um dos aspectos mais importante desta participação reserva-se para a parte ainda mais informal da diplomacia submersa. Acontece que após a realização de qualquer workshop, conferência, que consideramos o momento de confraternização que se designa por hallway chats, ou seja, as conversas de corredor, onde são afloradas as questões mais sensíveis, de forma muito descontraída. Nestas interacções ou troca de opiniões, os representantes chineses costumam aligeirar as posições oficiais, funcionando como Confidence Building Measures (CBMs), o que simultaneamente os coloca na acção preventiva do conflito (LANTEIGNE, 2005, p. 96). A verdade é que o CSCAP, apesar das restrições, tornou-se o único fórum multilateral de segurança na qual as delegações de Taipé e Pequim tiveram a oportunidade de interagir e trocar pontos de vista sobre a segurança regional (CHYNGLY, 2005, p. 63). Quanto maiores forem os laços criados e as janelas de oportunidade usadas, maiores serão os custos políticos com uma possível confrontação. Ao mesmo tempo, a participação de Pequim em organismos como a ASEAN, ARF e o CSCAP concedem uma função pedagógica ao obrigar a China a entrar numa ordem regional, entre numa lógica de cooperação, fortaleça a diplomacia preventiva e limite as soluções militares. Com a reactivação do papel da SEF e da ARATS recuperando, por um lado, o espírito do Consenso de 1992, numa lógica bilateral, e por outro, em colaboração com as dinâmicas comunicacionais regionais de espírito multilateral, contribuem na construção de um estado de entendimento que permite a transformação do conflito. 


\section{Conclusão}

O conflito de Taiwan permanece na cena internacional como uma anomalia de natureza política, mais do que de natureza jurídica, deixando a ilha num estado de isolamento que limita a sua participação em muitos fora de discussão internacional. Sendo o conflito entre a China e Taiwan uma questão com possíveis repercussões regionais e até globais, seria importante levar esta matéria às plataformas de discussão sobre segurança, tal como o ARF, e envolver os actores especializados na transformação de conflitos. Não é assim o entendimento de Pequim, por considerar esta uma matéria da sua inteira responsabilidade, pelo que Taipé apenas através de alguns canais submersos vai conseguindo dialogar, não só directamente com Pequim, como com outros actores regionais. Em alguns casos, a pretexto de se discutirem temas de desenvolvimento económico, menos sensível, consegue-se chegar de forma ainda mais submersa às discussões de segurança. Destacamos o CSCAP, que pela sua natureza eminentemente submersa, permite que individualidades da China e Taiwan discutam matérias importantes no âmbito da economia e da segurança. Muitas das ideias e sugestões ali desenvolvidas são levadas ao conhecimento dos responsáveis políticos, sendo capazes de alterar comportamentos e até mentalidades e, neste sentido, acabam por funcionar como janelas de oportunidade para a transformação do conflito.

\section{The international condition of Taiwan and the opening of diplomatic channels submerged as window of opportunity: the case of CSCAP}

\section{Abstract}

The present essay focuses on the unique case of the island of Taiwan, $a$ de facto, but not de jure state in the Asian context, lacking recognition from the international community, which leaves the territory in an exceptional state of isolation in the global institutional architecture. Unable to participate in many regional organisms, especially those that focus on security issues, Taiwan cannot present to multilateral fora the conflict with the People's Republic of China (PRC). The islanders have benefitted from a set of processes and networks of submerged nature, led 
by non-official actors, of which The Council for Security Cooperation in the Asia

Pacific (CSCAP) has been a good example, and is here analysed.

Keywords: China. Taiwan. Conflict. Submerged diplomacy. Transformation. CSCAP.

\section{Referências}

BALL, Desmond et. al. Track 2 Security Dialogue in the Asia-Pacific: Reflections and Future Directions. Asian Security, v. 2, n. 3, p. 174-188, 2006.

BOAO Forum for Asia. Disponível em: <http://www.boaoforum.org/ Html/homeen.asp>. Acesso em: 24 mar. 2010.

CHYUNGLY, Lee Conflict Prevention in Northeast Asia: theoretical and Conceptual Reflections. In: SWANSTROM, Niklas (Ed.) Conflict Prevention and Conflict Management in Northeast Asia. Uppsala/Washington: Central Asia Caucasus Institute \& Silk Road Studies program. Central Asia-Caucasus Institute \& Silk Road Studies Program - A Joint Transatlantic Research and Policy Center, 2005, p. 51-68.

CUNHA, Luís. China: cooperação e conflito na questão de Taiwan. Lisboa: Prefácio, 2008.

DIAMOND, Louise; MCDONALD, John W. Multi-Track Diplomacy: a systems approach to peace. West Hartford: Kumarian Press, 1996.

EVANS, Paul M. Assessing the ARF and CSCAP. In: TIEN, Hung-mao; CHENG, Tun-jen (Ed.) The Security Environment in the Asia-Pacific: many problems, few building blocks. New York: ME. Sharpe, 2000. p. 154-172.

GARRISON, Jim; PHILIPPS, John-Francis. The New Diplomats: Citizens as Ambassadors for Peace. Devon: Green Books, 1989.

LANTEIGNE, Marc. China and International Institutions: alternative paths to global power. New York: Routledge, 2005.

LIBERTÉ, André. The Politics of Buddhist Organizations in Taiwan, 1989-2003: Safeguarding the Faith, Building a Pure Land, Helping the Poor. New York: Routledge, 2004. 
LIN, April C. J.; KEATING, Jerome F. Island in the Stream: A Quick Case Study of Taiwan's Complex History. Taipei: SMC Publishing, 2008.

MCDONALD, John. Guidelines for Newcomers to Track Two Diplomacy, Occasional Paper no. 2, Institute for Multi-Track Diplomacy. Arlington: IMTD, 1993.

MONTEIRO, Ramiro Ladeiro. A África na politica de cooperação europeia. Lisboa: Instituto Superior de Ciências Sociais e Politicas, 2001.

NOTTER, James; MCDONALD, John. Track Two Diplomacy: Nongovernmental Strategies for Peace. Denver: Institute for Multi-track Diplomacy, 1996.

SILVA, Jorge Tavares da. New Trends in the Taiwan Strait Conflict: the Cooperative and Quarrelsome Framework. In TOMÉ, Luis. (Ed.). East Asia Today. Lisboa: Prefácio, 2008. p. 321-340.

TAIWAN TODAY, Cross-strait leaders to talk business at Boao Forum, Disponível em: <http://www.taiwantoday.tw/ct.asp? xitem=98119\&CtNode=414. Acesso em: 28 mar. 2010.

ROGOFF, Barbara. Introduction: Thinking and Learning in Social Context. In ROGOFF, Barbara; LAVE, Jean (Ed.). Everyday Cognition: Development in Social Context. London: Havard University Press, 1999. p. 1-8.

WEISSMAN, Mikael. Peacebuilding in East Asia: The Role of Track 2 Diplomacy, Informal Networks, and Economic Social, and Cultural Regionalization. In: BERCOVITCH, Jacob et. al. (Ed.). Conflict Management, Security and Intervention in East Asia: Third-party Mediation in Regional Conflict. London \& New York: Routledge, 2008. p. 67-82.

WILLIAMS, Erin E.; JOB, Brian L. The Imperative of Multilateral Security Cooperation. In: JOB, Brian L. (Ed.). CSCAP Regional Security Outlook 2007. Vancouver: CSCAP, 2007. p. 1-12.

WOUTERS, Jan; RUYS, Tom. Security Council Reform: A New Veto for a New Century? Gent: Academia Press, 2005.

WU, Linjun. Limitations and Prospects of Taiwan's Informal Diplomacy. In: HENCKAETS Jean-Marie (Ed.). The International Status of Taiwan in the New World Order: Legal and Political Considerations. London: Kluwer Law International, 1996. p. 35-52. 


\section{Para publicar na revista Universitas}

Relações Internacionais, entre no endereço eletrônico www.publicacoesacademicas.uniceub.br. Observe as normas de publicação, facilitando e agilizando o trabalho de edição. 